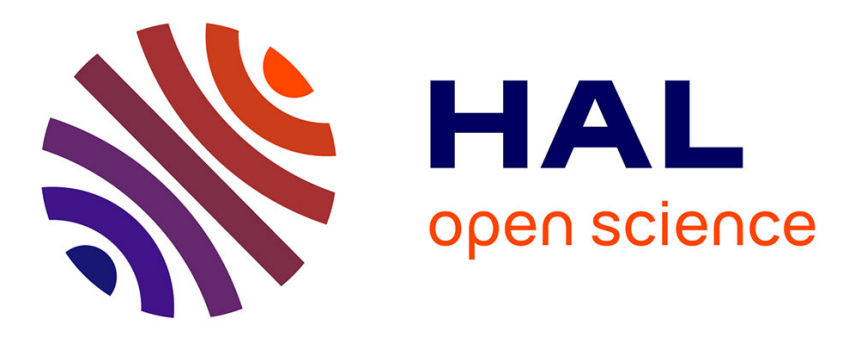

\title{
Behavioural and physiological reactions of piglets to gentle tactile interactions vary according to their previous experience with humans
}

Céline Tallet, Kardiatou Sy, Armelle Prunier, Raymond Nowak, Alain Boissy, Xavier Boivin

\section{To cite this version:}

Céline Tallet, Kardiatou Sy, Armelle Prunier, Raymond Nowak, Alain Boissy, et al.. Behavioural and physiological reactions of piglets to gentle tactile interactions vary according to their previous experience with humans. Livestock Science, 2014, 167, pp.331-341. 10.1016/j.livsci.2014.06.025 . hal-01129853

\section{HAL Id: hal-01129853 \\ https://hal.science/hal-01129853}

Submitted on 27 May 2020

HAL is a multi-disciplinary open access archive for the deposit and dissemination of scientific research documents, whether they are published or not. The documents may come from teaching and research institutions in France or abroad, or from public or private research centers.
L'archive ouverte pluridisciplinaire HAL, est destinée au dépôt et à la diffusion de documents scientifiques de niveau recherche, publiés ou non, émanant des établissements d'enseignement et de recherche français ou étrangers, des laboratoires publics ou privés. 
Behavioural and physiological reactions of piglets to gentle tactile interactions vary according

2 to their previous experience with humans

3

4

5 Céline Tallet $^{\text {ab }}$, Kardiatou Sy ${ }^{\mathrm{a}}$, Armelle Prunier ${ }^{\mathrm{ab}}$, Raymond Nowak ${ }^{\text {cdef }}$, Alain Boissy ${ }^{\text {gh }}$, Xavier

6 Boivin $^{\text {gh }}$

7 a INRA, UMR1348 PEGASE F-35590, Saint-Gilles, France

8

9

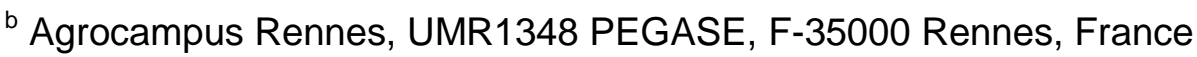

' INRA, UMR85 Physiologie de la Reproduction et des Comportements, 37380 Nouzilly,

France

${ }^{d}$ CNRS, UMR7247, 37380 Nouzilly, France

e Université François Rabelais de Tours, 37041 Tours, France

${ }^{\mathrm{f}}$ Institut Français du Cheval et de l'Equitation, 37380 Nouzilly, France

${ }^{g}$ INRA, UMRH1213 Herbivores, F-63122 St Genes Champanelle, France

${ }^{\mathrm{h}}$ Clermont Université, VetAgro Sup, UMR Herbivores, BP 10448, F-63000, Clermont-

Ferrand, France

17

18

19

* Corresponding author: Céline Tallet; celine.tallet@rennes.inra.fr; tel: 0033 (0)2 234850 53; fax: 0033 (0)2 234850 80. INRA, UMR1348 PEGASE,

Domaine de la Prise, F-35590 St Gilles, France 
Abstract

Providing piglets with repeated stroking and brushing leads to behaviours of affinity towards their handler, but there is still no evidence of physiological modifications. In addition, other tactile stimulations like scratching have not yet been studied while there are used by pigkeepers. In Thus, the present experiment aimed at determining the consequences of stroking and scratching weaned piglets on their later behavioural, cortisol and cardiac responses to human presence and gentle tactile interactions. Four groups of four piglets were weaned at 28 days of age (Day 0) and handled twice a day for 10 min, five days a week, from Day 1 to 28. Handling consisted in standing for $30 \mathrm{~s}$, sitting for 1 min and then stroking and scratching each piglet for $2 \mathrm{~min}$. Four groups of four piglets were used as controls and received only the minimal contacts for routine husbandry practices. Behavioural reactions to the presence of the handler in the home pen (Day 25) and to her presence and departure were observed in an arena test (Days 26-27). Behavioural and cardiac responses to the handler's presence and contact were compared in a test pen (Days 33-35). Salivary cortisol levels were measured in another test pen after 15-min of either contacts with the handler or isolation (Days 40-43). In the home pen, handled piglets investigated sooner the handler $(P<0.001)$ and spent more time investigating her than control piglets $(P<0.05)$. In the arena test, handled piglets investigated sooner the handler $(P<0.01)$ and spent more time close to the handler than control ones $(P<0.01)$. Heart rate of the piglets during stroking and scratching did not differ between treatments but the root mean square of successive differences in heart beat intervals was lower in handled than in control piglets when the rear part of the body was scratched $(P<0.01)$. There was no effect of the previous experience with the handler on salivary cortisol levels $(P>0.05)$. Overall this study shows that scratching and stroking piglets during three weeks after weaning changed the way that they interacted with the handler, being more attracted than control piglets. However, there was no clear difference in cardiac reactions to scratching and stroking between handled and control piglets, suggesting that these contacts are perceived positively, regardless of the previous experience. The body region stimulated may be of importance but it needs further investigation. 
51 Keywords: pigs, human-animal relationship, behaviour, cardiac activity, cortisol

52 
1. Introduction

Many studies showed that a positive human-animal relationship may develop in farm animals like pigs, cattle, sheep, horses or poultry (Waiblinger, 2009; Hemsworth and Coleman, 2011). A positive relationship is notably characterised by an absence of fear reactions to humans and an easiness to handle the animals (Waiblinger et al., 2006). It is favourable to animal welfare and also enhances performances (Boivin et al., 2003; Hemsworth, 2008) and may be a source of positive emotions for farm animals (e.g. Tallet et al., 2005; Schmied et al., 2008). Among the interactions with humans that can be perceived as positive, food provision is an efficient way of attracting animals (i.e. Hemsworth et al., 1996b; Jago et al., 1999; Sankey et al., 2010). Gentle tactile interactions have also been tested as a potential way to decrease fear of humans and to increase attraction to them. In farm animals, this has mainly been investigated in cattle, sheep and horses. Although some studies do not show a beneficial effect of gentle tactile stimulations on perception of humans (Boivin et al., 1998; Jago et al., 1999; Hausberger et al., 2008) most of them indicate that such stimulations are a source of positive reactions towards humans and induce a decrease of behavioural reactions of fear in human presence (e.g. Becker and Lobato, 1997; Tallet et al., 2005; Tallet et al., 2011a; Tallet et al., 2011b; Probst et al., 2012). Very few data are still available in farm animals regarding the consequences of gentle tactile stimulations on physiological indicators of stress like cortisol level and heart rate. In beef cattle, gentle touching in early age seems to dampen the cortisol release at slaughter (Probst et al., 2012) while the reduction is not always significant when applied only few weeks before slaughtering (Mattiello et al., 2010). Likewise, gentle stroking has been shown reduce heart rate increase during a veterinary procedure (Schmied et al., 2010) or in presence of the handler in an arena test (Raussi et al., 2003; Tallet et al., 2006) in cattle and sheep. To our knowledge, the influence of gentle contact on the physiological indicators of stress has been poorly investigated in pigs. The cortisol release of pigs after human exposure was analysed only in two studies (Hemsworth et al., 1986a; Paterson and Pearce, 1992) and both of them did not show clear effects but the numbers of pigs studied were very low (four or seven pigs in each group). 
In the literature on farm species, different types of tactile contact were applied to the animals like stroking (i.e. Tallet et al., 2005 in sheep), brushing (i.e. Tanida et al., 1994 in pigs), simply touching (i.e. Breuer et al., 2003 in cattle) or holding the animals (Tallet et al., 2009 in sheep) but they were rarely compared. All these types of interactions may be given by stockpeople, either at distinct moments or during a (usually short-lasting) sequence of interactions. Besides the quality of the interactions, the body region being touched is important for the animals as shown in cattle (Schmied et al., 2008) and rats (Grandin, 2010). In the study of Schmied et al (2008), cows expressed more positive reactions (e.g. neck stretching) to stroking at the withers and neck ventral regions than at the lateral chest. This could be related to the intra-specific social behaviour since intra-specific physical interactions are directed to preferential parts of the body in cattle for instance (in cattle: Val-Laillet et al., 2009; Laister et al., 2011) and the human stimulation of the preferred area are more effective on relaxation postures and physiological indicators compared with other regions (Schmied et al, 2008).

The importance of the type of gentle tactile stimulations has been less investigated in pigs than in cattle or sheep. Yet pig-keepers also interact physically with their animals and pigs are social animals which may interact physically with their keeper as well $p$ (Hemsworth, 2008). At the intra-specific level, tactile contact (nosing, nibbling, huddling) are important and pigs are used to rest in close body contact (Hafez, 1975). Pigs perform soft contact with their nose (Camerlink and Turner, 2013) or more dynamic contact looking like udder massages around nursing (Torrey and Widowski, 2006). Thus an influence of tactile human contact on the subsequent reactions of pigs to humans is expected. In pig production, human gentle interactions may take the form of stroking, touching but also scratching (personal observations). Stroking could mimic nosing while scratching that involves greater pressure than nosing would mimic massage. Pigs that are stroked whenever they approach a human during training sessions express subsequent contact seeking (Hemsworth et al., 1986a; 
Paterson and Pearce, 1992). To our knowledge, the influence of scratching has not been studied, while it is used by pig keepers and may have different consequences from stroking. Tanida et al (1994) used brushing which is close to scratching but differs from it because of the presence of an object between the animal and the human. They observed that, after two weeks of treatment, pigs spent more time in contact with humans when they had been brushed than when they had been stroked. However, in this study, brushing lasted 15 min per week whereas the duration of stroking depended on the willingness of the pig to approach the human; the amount of stimulation could have thus influenced the behavioural response of pigs. In all reported experiments, the body region exposed to the stimulation was never specified suggesting that there was no target region, but that interactions were probably provided all along the pigs' back. To our knowledge, no favourite body region was reported for pigs' social interactions but the rear part of the body could be more often concerned than the head (personal observation). The head and neck are rather preferential locations for aggressive interactions (Turner et al., 2006).

The present experiment aimed at determining the consequences of stroking and scratching weaned piglets on their later behavioural, cortisol and cardiac responses to human presence and to tactile interactions. The following hypotheses were tested: $1 /$ repeated gentle contact including stroking and scratching leads to a positive relationship with human, $2 /$ the reactions to different tactile contact depend on the previous experience with these stimulations.

\section{Material and methods}

The design of the experiment was approved by the local ethic committee (Comité Rennais d'Ethique en matière d'Expérimentation Animale, number R-2010-CT-02).

\subsection{Animals and rearing conditions}

We studied 32 female piglets (Sus scrofa domesticus) allocated to two treatments after weaning. They were born at the experimental unit of Saint-Gilles (INRA, France) from 11 

days of age (Day 0) and transferred to a new building where they were housed in groups of four in a single room. Weaning weight was similar in all groups varying from $7.3 \pm 0.7 \mathrm{~kg}$ to $7.6 \pm 0.6 \mathrm{~kg}$ (mean \pm SEM within the groups). Siblings were never housed in the same pen, and piglets from one litter were equally allocated to both treatments. The pens measured 1.2 $\mathrm{m} \times 1.3 \mathrm{~m}$ and consisted of slatted floor. The temperature was automatically set at $26^{\circ} \mathrm{C}$. The animals were fed with a standard weaning diet and had ad libitum access to food and water. Food was provided from outside the pen by the stockperson, twice a day. He took advantage of this presence in the room to visually check the health status of the animals. No health troubles were observed during the experiment, and so there was no other specific intervention of the stockperson.

\subsection{Treatments}

Minimal human contact, $\mathrm{HO}$ : Control animals from four rearing pens received the minimal amount of daily contact with a stockperson (a $1.70 \mathrm{~m}$ high male) required for feeding, cleaning and health checking. The stockperson wore dark green shirt and pans with brown shoes.

Additional human contact, $\mathrm{H} 1$ : Animals from the four other rearing pens received, in addition to daily care given by the stockperson as for $\mathrm{HO}$, gentle tactile contact from a handler (a 1.65 $\mathrm{m}$ high woman), who wore the same overalls and boots each time she interacted with the pigs; i.e. blue overalls and dark green boots. This additional contact was given from the day after weaning and lasted for three and a half weeks (till Day 25, Table 1), with two sessions per day (except at weekends). Human contact was standardised and consisted in entering the pen and staying immobile for $30 \mathrm{~s}$, then sitting on a bucket and remaining motionless for $1 \mathrm{~min}$, and finally giving gentle tactile contact to each animal for $2 \mathrm{~min}$. The last phase was adapted to the reaction of each animal and included four steps: 1), the handler hold out the hand towards the animal; 2) if the piglet did not move away, the handler tried to touch it; 3) if it accepted being touched, the handler softly stroked it along the body with the palm of her 
hand; and 4) once it accepted being stroked, the handler scratched it along the body with her fingers. Scratching consisted in rubbing the skin of the piglets with the finger tips and applying more pressure than stroking. The handler provided the stimulation at a rhythm of 3 per second on about $20 \mathrm{~cm}$ of length. In addition, the handler spoke to the piglet with a soft voice.

\subsection{Measurements}

Test 1. Behaviour towards the handler in the rearing pen at the end of the treatment period (Day 25, Table 1). We compared the behavioural reaction of $\mathrm{H} 1$ and $\mathrm{HO}$ piglets to the presence of the handler in their home pen. The animals were identified with a number on their back. The handler entered the home pen and stood motionless for $30 \mathrm{~s}$. Then, she sat in the centre of the pen and remained motionless without interacting with the animals for 2 min. From videos, the interactions with the handler (looking towards and entering in contact with the handler, details in Table 2) were recorded. The latency and duration of each item as well as the number of interactions were calculated for the total observation period.

\section{Test 2. Behaviour towards the handler presence and then departure in an arena test (Days} 26-27, Table 1). We compared the behaviour of $\mathrm{H} 1$ and $\mathrm{HO}$ piglets to the handler (her presence and absence) in a testing room $(3 \mathrm{~m} \times 3 \mathrm{~m})$. The floor was divided in 16 identical zones $(0.75 \mathrm{~m} \times 0.75 \mathrm{~m})$ by painted lines. The piglets were individually transported to the testing room by a disguised stockperson using a cart on wheels filled with straw. The disguised person (male) wore white coveralls, a white mask, white gloves, sun glasses and was perfumed in order to avoid individual recognition by the piglets. The test consisted in three phases of 2 min each: 1 . The handler sat in the middle of a wall of the testing pen. She interacted with the piglet if it made contact with her; 2 . The handler left the room and the piglet remained alone for $2 \mathrm{~min} ; 3$. The handler came back at the same place for $2 \mathrm{~min}$. The testing order and the location of the handler (left/right wall of the test pen) were organized to alternate according to the pen and treatment of the animals. An experimenter who was not 
visible by the animals counted the vocalisations (Table 2) during the test. Locomotor activity, behaviours directed to the handler (Table 2) and the time spent very close to the handler (corresponding to the two zones in which the handler was present) were determined from video records. Due to one missing video record, 15 observations for the $\mathrm{H} 1$ treatment and 16 for $\mathrm{HO}$ treatment were analysed.

Test 3. Changes in behavioural and cardiac activities according to the handler's behaviour in a test pen (Days 33-35, Table 1). The test aimed at comparing the reactions of the piglets to strokes and scratches. This test was performed in the same room as Test 2 , but in a smaller pen having the shape of a quarter circle. The two perpendicular walls were $1 \mathrm{~m}$ long so that the handler could easily touch the animal, even if it did not come close to her. It also reduced the piglets' locomotor activity, limiting the influence of the physical activity on the cardiac activity.

Thirty minutes before the test, each animal was fitted with an elasticised belt by a disguised experimenter (similar as in Test 1 ) and stayed in its home pen so that it had time for getting used to the belt before being tested. Then, each piglet was individually transported to the testing room in the same manner as in Test 1. In the testing room, the telemetric recording apparatus (Polar Vantage NV, Elektro Oy, Helsinky, Finland) was fixed to the sternum, under the belt, by two disguised experimenters. The test was divided in six phases of 2 min: 1 . Isolation in the test pen ("alone"); 2. The handler entered and sat on a bucket in the pen ("Hsat"); 3. The handler stroke the animal all along the body ("strok1"); 4. The handler scratched the animal on its head ("scratH"); 5. The handler stroke the animal all along the body again ("strok2"); and 6. The handler scratched the animal on its rear ("scratR"). The testing order was organised according to the pen and treatment of the animals. An experimenter counted the vocalisations (Table 2) during the test via The Observer XT 9.0 (laptop). The behaviours directed to the handler and escape attempts were video recorded (Table 2). 
Cardiac activity data were transferred from the receiver to a computer equipped with Polar HR Analysis 5.04. and exported in text files. Each text file was carefully analysed in order to delete the errors corresponding to abnormal durations between heart beats probably due to connection problems (Marchant-Forde et al., 2004). Heart rate $(\mathrm{bpm}=$ number of beats per min) and time interval (in ms) between two consecutive beats were calculated. To evaluate the heart rate variability and hence the vagal tone, the root mean square of successive differences (RMSSD) in inter-beat duration was calculated (Porges, 1995; von Borell et al., 2007) (Porges, 1995; von Borell et al., 2007). Mean bpm and RMSSD were calculated on each 2-min phase of the test as well as on the first and last $10 \mathrm{~s}$ of each phase. Due to technical problems and to a very high physical activity on two animals, data on 2-min phases were analysed in $11 \mathrm{H} 1$ and $12 \mathrm{H} 0$ piglets. For the 10-s sequences, data from some more animals could not be analysed (too much missing values) and the sample size is reported in the results section (Table 3).

Test 4. Cortisol responses to isolation and human contact in a test pen (day 40-43, Table 1).

The test aimed at comparing the cortisol level of the piglets after either 15 min of isolation or 15 min of human contact. The timing was chosen from a previous experiment published with the same method as us, showing that salivary cortisol peak is expressed 15 minutes after the stressor started (Merlot et al., 2011, Ruis et al., 2001). It was performed in the same room as Tests 2 and 3 but in a triangular area delimited in a corner of the room ( $1 \mathrm{~m} \times 1 \mathrm{~m} \times 1.4 \mathrm{~m})$. In this way, the handler could easily touch the animal, even if it was not willing to come into contact. The piglets were individually transported to the testing room in the same manner as in Test 1. Animals were tesed in both situations two days apart, at the same time of the day. Each test lasted 15 min. During the test in human presence, the handler was asked to stroke and scratch regularly the piglet. The testing order was organised according to the treatment of the animals and their pen in a cross-over design. The behaviours directed to the handler were video recorded (Table 2). To obtain saliva for measure of cortisol levels, at the end of the test, the handler gave the piglet a cotton bud to chew until it was moistened. Cotton buds 
were immediately centrifuged at $3000 \times \mathbf{g}$ for $15 \mathrm{~min}$ at $4^{\circ} \mathrm{C}$. Saliva samples were stored at $-20^{\circ} \mathrm{C}$ until assay. Cortisol was assessed using an immuno-luminescence assay (LIA, IBL, Hamburg, Germany) as described by Merlot et al. (2012).

251

252

\subsection{Recording of piglet behaviour}

253 Treatment sessions and all the tests were video recorded with a camera (Panasonic PC252230P33) fixed above the pen linked to a computer equipped with a video acquisition card and Mpeg recorder (Noldus, Netherlands). From the videos, the behaviour was analysed during each testing phase with The Observer XT9.0 (Noldus, Netherlands). We carried out continuous behavioral observations using all pigs as focal animals, even during Test 1 (all the pigs were observed).

\subsection{Statistics}

The animal was used as the statistical unit for all measures. The general procedure for the analyses consisted in running repeated ANOVA analysis (MIXED procedure of SAS 9.2, SAS Institute Inc.). For Tests 2 and 3, the model included the treatment ( $\mathrm{HO}$ and $\mathrm{H} 1)$, phase of the test (repeated variable, 1.human presence, 1.isolation, 3.human presence), and their interaction. The place of the handler in Test 2 (left or right) was also included in a preliminary model, but as it was never significant, it was removed from the final analyses. For Test 4 , the model included the treatment, the testing condition (isolation or human presence) as a repeated factor and their interaction. The animal identity was used as a random factor for all models. For all the models, post hoc comparisons after ANOVA were run using Least Square Differences (LSD). In order to normalise the distribution of the residual of the models and meet criteria for parametric statistics, some data (Test 3: RMSSD; Test 4: cortisol level) were

272 transformed by $\log (n+1)$ (Martin and Bateson, 1994). When the criteria for parametric

273 statistics could not be met (Test 1, Test 3: behaviour, cardiac activity parameters $10 \mathrm{~s}$ before 274 and after the start of each phase of the test, Test 4: behavioural data), non-parametric tests 275 (Mann-Withney for the treatment effect, Friedman time effect) were performed (Statview, 5.0, 
SAS Institute Inc.). Values are presented as means \pm standard errors of means of nontransformed data (after ANOVA) or as medians and interquartiles (IQ, after Mann-Whitney test).

Spearman correlations were calculated to determine potential links between behaviour and cardiac activity during Test 3 (SAS 9.2, SAS Institute Inc.). The rare behaviours (i.e. climbing on the human) were analysed by comparing the number of animals by treatment performing the behaviour with a modified version of the Chi2 test better suited to small samples: the $2 \hat{\imath}$ test (Arbonnier, 1966).

Results were considered as significant when the probability of the null hypothesis was less than or equal to 0.05 .

\section{Results}

During the handling sessions, all the $\mathrm{H} 1$ piglets accepted being gently touched from session 6 onwards and approached the handler when she entered the pen from session 13 onwards.

\subsection{Test 1. Behaviour towards the handler in the home pen at the end of the handling} sessions

While the handler was standing (30 s), $11 \mathrm{H} 1$ piglets investigated her but only one $\mathrm{HO}$ piglet did so $(2 \hat{\imath}=15.0, P<0.001)$. Instead, the HO piglets looked at her more often $(N=10$, versus $N=3 \mathrm{H} 1$ piglets, $2 \hat{\imath}=6.62, P<0.05)$. While the handler was sitting for $2 \mathrm{~min}, \mathrm{H} 1$ piglets investigated her sooner (H1: $2.7 \mathrm{~s}(1.2-4.7 \mathrm{~s}) ; \mathrm{H0}: 78.9 \mathrm{~s}(29.1-114.1 \mathrm{~s}) ; U=33, P<0.001)$ and for a longer duration than $\mathrm{HO}$ piglets $(\mathrm{H} 1: 74.4 \mathrm{~s}(50-97 \mathrm{~s}) ; \mathrm{HO}: 1.5 \mathrm{~s}(0-34.3 \mathrm{~s}) ; \mathrm{U}=27, P$ $<0.001)$. Six $\mathrm{H} 1$ piglets were observed climbing on her but no $\mathrm{H} 0$ piglets $(2 \hat{\imath}=9.71, P<$ 0.01). More $\mathrm{H} 1$ than $\mathrm{H} 0$ piglets were observed being in contact with her $(\mathrm{H} 1: N=16, \mathrm{HO}: N=$ 9, $2 \hat{\imath}=11.69, P<0.001)$, but less $\mathrm{H} 1$ piglets looked at her $(\mathrm{H} 1: N=4, \mathrm{H} 0: N=12,2 \hat{\imath}=8.37$, $P<0.01)$. Only $\mathrm{H} 0$ piglets expressed avoidance reactions $(N=15)$.

\subsection{Test 2. Behaviour towards the handler presence and departure in the arena test.}


$\mathrm{H} 1$ piglets approached the handler sooner $(\mathrm{H} 1: 86 \pm 6 \mathrm{~s} ; \mathrm{H0}: 111 \pm 6 \mathrm{~s} ; F 1,30=9.14$, $P=0.005)$ and stood for a longer time near her $(F 1,30=12.7, P=0.001$, Figure 1$)$ than $\mathrm{H} 0$ piglets. $\mathrm{H} 1$ piglets investigated the handler sooner than $\mathrm{HO}(\mathrm{H} 1: 81 \pm 7 \mathrm{~s} ; \mathrm{HO}: 103 \pm 7 \mathrm{~s}$; $F 1,30=4.67, P=0.04)$ but for a similar duration $(\mathrm{H} 1: 4.2 \pm 1.7 \mathrm{~s} ; \mathrm{HO}: 4.8 \pm 1.6 \mathrm{~s} ; F 1,30=$ $0.05, P=0.82)$. Independently of the treatment, the animals approached and contacted the handler sooner, and for a longer duration (see Figure 1 for the time spent near the handler) in phase 3 compared with phase $1(P<0.05)$. There was no interaction between treatment and phase of the test $(P>0.05)$ for the preceding variables. We found a significant phase $\mathrm{x}$ treatment interaction for the time spent looking at the handler $(F 1,28=7.27, P=0.01)$ : it increased between phase 1 and 3, and $\mathrm{HO}$ piglets spent more time looking at the handler than $\mathrm{H} 1$ piglets during phase 3 (Figure 1$)$. There was no significant effect of treatment $(F 1,30$ $<0.71, P>0.05)$ or phase $(F 2,57<1.16, P>0.05)$ and no interaction $(F 2,57<2.61, P>$ $0.05)$ for the number of zones crossed (18 \pm 2 zones) and the number of low-pitched vocalisations (18 \pm 2 times). No high-pitched vocalisations were emitted.

\subsection{Test 3. Changes in behavioural and cardiac activities according to the handler's} behaviour in the test pen.

\section{Behaviour}

The number of vocalisations, the time spent investigating the handler and the time spent without contact with the handler evolved significantly along the phases (Friedman test, $\mathrm{P}<$ 0.04, see Figure 2). At the beginning of the test (Hsat phase), $\mathrm{H} 1$ piglets expressed more low-pitched vocalisations than $\mathrm{HO}$ piglets $(U=71, P=0.03)$. In addition, more $\mathrm{H} 1$ than $\mathrm{HO}$ piglets expressed high-pitched vocalisations $(\mathrm{H} 1: N=9, \mathrm{HO}: N=2 ; 2 \hat{\imath}=7.20$, ddl $=1 ; P<$ 0.01). $\mathrm{H} 1$ piglets investigated sooner the handler $(\mathrm{H} 1: 2.0 \mathrm{~s}(\mathrm{IQ}=5.8 \mathrm{~s}))$ than $\mathrm{HO}$ piglets $(\mathrm{HO}$ : $16.8 \mathrm{~s}(\mathrm{IQ}=46.6 \mathrm{~s}) ; U=40, P<0.001)$ and more $\mathrm{H} 1$ piglets climbed on the handler $(\mathrm{H} 1: N=$ 8, $\mathrm{HO}: N=2, \mathrm{ddl}=1 ; 2 \hat{\imath}=5.31, P<0.05)$. There was no significant treatment effect on the time spent investigating the handler $(P>0.05$, Figure $2 b)$. During the second and third phases of the test (Strok1 and ScratH), HO piglets spent less time without contact with the 
handler, $(U<61, P<0.01)$. During the subsequent phases, here was no significant

difference $(P>0.1$, Figure 2c).

\section{Cardiac activity}

There was no interaction between treatment and phase $(F 5,87=1.42, P=0.23)$ and no effect of the treatment on the heart rate $(F 1,22=0.12, P=0.73)$ but the phase effect was significant $(F 5,87=13.49, P<0.0001)(F i g u r e 3 a)$ : heart rate decreased significantly between "ScratH" and "Strok2" phases. The interaction between treatment and phase was significant for RMSSD $(\log , F 5,87=3.42, P=0.007)$, i.e. there was no difference at the beginning but the evolution of the mean RMSSD differed between the treatments (Figure 3b). For HO piglets, the mean RMSSD decreased until the "ScratH" phase and then increased until the end of the test to reach the same level as in the beginning of the test. For $\mathrm{H} 1$ piglets, the mean RMSSD decreased to the end of the test. During the last phase ("ScratR"), the RMSSD was significantly higher for $\mathrm{H} 0$ than for $\mathrm{H} 1$ piglets (Figure $3 b$ ).

Comparing the last ten seconds of a phase with the first ten seconds of the following phase (immediate response) demonstrated differences between treatments (Table 3). The heart rate increased from the "alone" to the "Hsat" phase for $\mathrm{HO}$ and $\mathrm{H} 1$ animals. It decreased for H1 animals between "scratH" and "strok2" and between "strok2" and "scratR", but did not evolve for $\mathrm{HO}$. There was no significant difference of RMSSD between last ten seconds of a phase and first ten seconds of the following phase $(P>0.05)$.

\section{Correlations between behaviour and cardiac activity}

The heart rate was negatively correlated with the time spent without contact with the handler during the "Hsat" phase for piglets from the $\mathrm{HO}$ treatment $\left(R_{S}=-0.73, P=0.007\right)$. The RMSSD was negatively correlated with the time spent lying down without contact to the handler for $\mathrm{H} 0\left(R_{S}=-0.80, P=0.006\right)$ and $\mathrm{H} 1\left(R_{S}=-0.84, P=0.005\right)$ piglets during the "Strok2" phase. In addition, for H1 piglets, the RMSSD was positively correlated with the time spent investigating the handler $\left(R_{S}=0.69, P=0.04\right)$ and with the time spent without contact with the handler $\left(R_{S}=0.67, P=0.05\right)$. 

pen

362

363

364

365

366

367

There was no interaction $(F 1,30=0.00, P=0.97)$ between the testing condition (isolation versus human contact) and the treatment ( $\mathrm{HO}$ versus $\mathrm{H} 1)$ on the salivary cortisol concentration as well as no effect of the testing condition (isolation versus human contact, $\log , F 1,30=1.29, P=0.27)$ nor of the treatment $(\mathrm{H} 0$ versus $\mathrm{H} 1, F 1,30=0.65, P=0.43$, Figure 4).

During human presence, more $\mathrm{H} 1$ than $\mathrm{H} 0$ piglets were observed climbing on the handler (8 versus $1,2 \hat{\imath}=8.36, \mathrm{ddl}=1, P<0.01$ ). There was no effect of the treatment on the latency, duration and number of other behaviours $(U>128, P>0.05)$ whatever the phase of the test.

\section{Discussion}

4.1. Consequences of being repeatedly stroked and scratched on subsequent responses to the handler

After three weeks of gentle human contact consisting of stroking and scratching, handled piglets expressed a higher attraction to the handler than control piglets. This was true until at least six weeks after the beginning of the handling sessions. To our knowledge this is the first time that scratching was used as a tactile interaction provided by humans. This method seemed to be a positive way of interacting with animals when associated with stroking. It remains to determine the relative importance and valence of both tactile stimulations (scratching and stroking) in the development of the positive relationship in weaned piglets.

The attraction to the handler was characterized by approaches and contact with her. The duration of interactions of handled piglets with the handler reached almost two third of the duration of the test in the home pen and one third of the duration of the test in the test pen, showing the high interest of piglets for the human handler in both situations. However it seemed rather low in the arena test (a large pen) compared with the other tests and to previous studies in comparable conditions (e.g. Hemsworth et al., 1996a; Day et al., 2002). 
In the home pen, the physical and social environments were familiar to the piglets, and so piglets probably felt confident in getting in contact with the handler. In the test pen, the space available was limited, so only fearful piglets stood against the walls of the pen not to be in contact with the handler. On the contrary, the arena test associated novelty of the environment and a large space (more than twice the size of the home pen). It took almost $1 \mathrm{~min} 30 \mathrm{~s}$ to the handled pigs to get in contact with the handler, which appears to be higher than in preceding studies reporting a latency of about $30 \mathrm{~s}$ (e.g. Hemsworth et al., 1986b). In previous studies, individual handling took place where the arena test was performed, and so handled pigs were used to the experimental environment. This was not the case in our arena test, which was a novel environment for the piglets. This can easily explain why it took them more time to get in contact with the human, as the novelty of the situation probably induced cautious reactions. This is confirmed by the increase in time spent interacting with the handler between the two phases of the test, both for handled and control piglets. After four minutes in the arena test, piglets may have been habituated to the environment and thus may be more confident for interacting with the handler. It can also be hypothesized that piglets arriving in a new environment are motivated to explore it and that there is a conflict of interest between the motivation to explore the new environment and to get in contact with the human with the balance changing over time in favour of the human.

We also observed that handled piglets climbed repeatedly on the human. To our knowledge, this behaviour has never been taken into account per se in preceding studies in pigs that report interactions as a whole. In lambs climbing is a behavioural expression of a higher attraction to a human handler (Tallet et al., 2009). This behaviour is also expressed in the mother-young relationship (Keeling and Gonyou, 2001). In our experiment, this could reflect a search for a more intensive contact with human by the piglets. These behavioural responses expressed by handled piglets are probably expressions of affinity for the handler as shown in lambs by Markowitz et al (1998). Thus climbing should be taken into account in the description of the interactions between pigs and humans. 
Control piglets preferentially expressed reactions characteristics of fear and avoidance (i.e. being far from the human handler, looking at the handler). Orientation of the head towards a stimulus is often displayed when an animal faces novel or aversive stimuli (i.e. Nagasawa et al., 2009; Kanitz et al., 2014 in press). Control animals were not familiar to the handler before the test sessions, even if they were used to human contact for routine husbandry tasks, feeding for instance. Consequently the handler could have been perceived as aversive or as a potential danger, even more that she was a woman while the stockperson was a man. The gender difference may have strengthened the novelty of the handler. Handled and control piglets differed in their reaction to the handler, but they did not show any difference in their behavioural and physiological reactions to social isolation in the different tests. This is in line with previous studies in domestic chicks or pigs (Jones and Waddington, 1992; Tallet et al., 2009).

In addition to behavioural parameters, we compared salivary cortisol level after isolation and after exposure to the handler. We did not find any significant difference even if the mean cortisol level seemed to be lower after human presence. There was also no significant effect of the previous handling treatment on cortisol levels either after isolation or human contact. This is in agreement with previous studies on low numbers of piglets (Hemsworth et al., 1986a; Paterson and Pearce, 1992). Introduction in a new environment for an open-field test is generally sufficient to induce an increase in cortisol level at 10 min after the start of the test (Zonderland et al., 2009) in pigs. After a stressor, the peak of salivary cortisol is generally expressed after 15 minutes (Merlot et al., 2011, Ruis et al., 2001). Therefore, the lack of difference between our treatments cannot be explained by a duration not sufficient to measure an adrenal response. Alternatively, it can be hypothesized that the situation itself, i.e. being taken away from the group, carried in a cart and put in an unfamiliar environment was stressful enough to induce a high adrenal response that would have masked the possible effect of the previous experience with the handler. Indeed, salivary concentrations measured in the pigs from the present experiment (about $4 \mathrm{ng} / \mathrm{ml}$ ) are much higher than 
those observed, with the same method, in growing pigs in their home pen (about $1 \mathrm{ng} / \mathrm{ml}$ ) (Merlot et al., 2012).

\subsection{Perception of the different types of gentle tactile contact in the test pen (Test 3)}

During the isolation phase of the test pen, vocalisations and heart parameters (heart rate, RMSSD) were similar in handled and control piglets. The heart rate was high at the beginning of the test since it was around $175 \mathrm{bpm}$ while resting heart rate of weaned piglets is about 130 bpm (Talling et al., 1996; Imfeld-Mueller et al., 2011). This may be due to the stress induced by the experimental procedure (transport, isolation from congeners, arriving in a new environment, fitting the recording device under a belt) even though care was taken to habituate the pigs to this experimental procedure as far as possible.

Once the handler entered the pen and sat down, handled piglets approached her more readily than control ones, climbed on her more frequently like in the other tests. They also expressed more high-pitched vocalisations which are indicators of stress in pigs (Weary et al., 1999; Schön et al., 2004; Tallet et al., 2013). These vocalisations could result from frustration due to the fact that the handler did not provide gentle tactile contact as expected by the handled piglets. This is supported by the fact that they did not express high-pitched vocalisations in the other phases of the test when they were touched. Terlouw and Porcher (2005) showed that repeated refusal of a stockperson to with positive tactile contact when they touch him progressively induces frustration behaviours as indicated by increased levels of locomotion, rubbing, immobility, and snout contact with the wall.

The arrival of the handler induced variations in the cardiac activity. Indeed, the heart rate during the first $10 \mathrm{~s}$ of presence of the handler was higher than the heart rate during the last $10 \mathrm{~s}$ of isolation for piglets of both treatments. Therefore, the arrival of the handler probably triggers excitement in piglets. In handled piglets, this excitement could be related to the expectation of positive tactile stimulation whereas in control piglets it is probably related to fear. Indeed, an increase in heart rate is often found in tests evaluating fear reactions 
(Forkman et al., 2007). This is supported by the observation that control piglets spent more

time without contact with the handler. Moreover, in those piglets, the correlation between the time spent away from the handler and the heart rate was positive and significant.

During the test, we observed time-related variations of the cardiac activity that are similar in both groups and suggest an overall similar perception of tactile contact regardless of the previous exposure to this contact. We demonstrated a general decrease of the heart rate that was similar in both treatments and was significant between the fourth and fifth phases of the test. We expected the heart rate to be lower after human arrival or during tactile stimulations in handled than in control piglets but this was not the case. One hypothesis is that stroking and scratching are spontaneously perceived as positive by piglets, and so induce the development of positive reactions along the test duration. Another hypothesis is that there is a very fast habituation to this novel gentle tactile stimulation by control piglets. This is supported by the fact that during the first phase of stroking, the control piglets spent more time without contact with the handler than handled piglets but afterwards this level was similar. The pre-exposure of control piglets to the handler in the preceding tests could have facilitated the process. However, the results have to be taken carefully due to the fact that the order of the phases was exactly the same for all animals, and thus the effect of the type of interaction is confused with the habituation to the testing conditions. Despite the absence of difference in heart rate, we observed different profile for the heart rate variability (i.e.

RMSSD). It decreased till the phase of scratching the head, increased afterwards in control piglets whereas it continued to decrease in handled piglets. RMSSD is known to increase in positive situations (Mohr et al., 2002; Reefmann et al., 2009b). This would mean that being scratched at the rear was perceived as positive by control piglets, but not by handled piglets. This is the first time that the effect of scratching was studied in piglets. Control piglets may have perceived this type of interactions given by the human as positive; while handled piglets would have developed habituation and absence of reaction. 
Despite the differences in the cardiac activity, there was no clear behavioural expression of

501 the differentiation between the two groups of pigs for scratching the rear. However, we did

502

503

504

505

506

507

508

509

510

511

512

513

514

515

516

517

518

519

520

521

522

523

524

525

526 not looked at more subtle behavioural expression of emotions, like tail movements or ear positions (Reefmann et al., 2009a) and differences in such parameters cannot be excluded. Another explanation is that, in many cases, the cardiac activity varies before observable behavioural modifications (von Borell et al., 2007), and thus the 2-min phases may have been too short to observe behavioural variations. This suggests that the cardiac activity is a very interesting tool to assess human-animal relationship and responses to precise categories of contact.

\section{Conclusion}

Providing both stroking and scratching to piglets for three weeks after weaning induced attractive reactions towards the handler both in their home pen and in an unfamiliar environment, revealing that they have developed an affinity towards the handler. The comparison of the heart rate activity between handled and control piglets did not provide any evidence of a different perception of these contacts according to the previous handling experience of the piglets. Piglets would be sensitive to human stroking and scratching in such way that these contacts are positively perceived by the animals even at the first exposure. Differences in the sensitivity of the different body regions will have to be further investigated.

\section{Acknowledgements}

This project was funded by the INRA PHASE division (Crédit incitatifs 2009). The authors thank Patrick Touanel, Michel Lefèbvre, Carole Guérin, Fabien Guérin and Xavier Averós for their active involvement in the experiment.

\section{References}


Arbonnier, P., 1966. L'analyse de l'information: aperçu théorique et application à la loi multimodale. Annales des Sciences Forestières 23, 950-1020 (Title translation: Information analysis: a theoretical view and the multinomial application).

Becker, B.G., Lobato, J.P., 1997. Effect of gentle handling on the reactivity of zebu crossed calves to humans. App. Anim. Behav. Sci. 53, 219-224.

Boivin, X., Garel, J.P., Durier, C., Le Neindre, P., 1998. Is gentling by people rewarding for beef calves? App. Anim. Behav. Sci. 61, 1-12.

Boivin, X., Lensink, B.J., Tallet, C., Veissier, I., 2003. Stockmanship and farm animal welfare. Animal Welfare 12, 479-492.

Breuer, K., Hemsworth, P.H., Coleman, G.J., 2003. The effect of positive or negative handling on the behavioural and physiological responses of nonlactating heifers. App. Anim. Behav. Sci. 84, 3-22.

Camerlink, I., Turner, S.P., 2013. The pig's nose and its role in dominance relationships and harmful behaviour. Applied Animal Behaviour Science 145, 84-91.

Day, J.E.L., Spoolder, H.A.M., Burfoot, A., Chamberlain, H.L., Edwards, S.A., 2002. The separate and interactive effects of handling and environmental enrichment on the behaviour and welfare of growing pigs. App. Anim. Behav. Sci. 75, 177-192.

Forkman, B., Boissy, A., Meunier-Sala $\square$ n, M.C., Canali, E., Jones, R.B., 2007. A Critical Review of Fear Tests Used on Cattle, Pigs, Sheep, Poultry and Horses. Physiology \& Behavior 92, 340-374.

Grandin, T., 2010. How to improve livestock handling and reduce stress. In: Grandin, T. (Ed.), Improving animal welfare - a practical approach. Cambridge University Press, Cambridge, pp. 64-87.

Hafez, E., 1975. The behaviour of domestic animals. Baillière tindall, London. Hausberger, M., Roche, H., Henry, S., Visser, E.K., 2008. A review of the human-horse relationship. App. Anim. Behav. Sci. 109, 1-24.

Hemsworth, P., 2008. Human-pig relationships. In: Faucitano, L., Schaefer, A.L. (Eds.), Welfare of pigs from birth to slaughter. Editions QUAE, Versailles (France), pp. 271-288. 
Hemsworth, P.H., Barnett, J.L., Hansen, C., 1986a. The influence of handling by humans on the behaviour, reproduction and corticosteroids of male and female pigs. App. Anim. Behav. Sci. $15,303-314$.

Hemsworth, P.H., Barnett, J.L., Hansen, C., Gonyou, H.W., 1986b. The influence of early contact with humans on subsequent behavioural response of pigs to humans. App. Anim. Behav. Sci. 15, 55-63.

Hemsworth, P.H., Coleman, G.J., 2011. Human-Livestock interactions, Second edition. CAB international, Chippenham, UK.

Hemsworth, P.H., Price, E.O., Borgwardt, R., 1996a. Behavioural responses of domestic pigs and cattle to humans and novel stimuli. App. Anim. Behav. Sci. 50, 43-56.

Hemsworth, P.H., Verge, J., Coleman, G.J., 1996b. Conditioned approach-avoidance responses to humans: the ability of pigs to associate feeding and aversive social experiences in the presence of humans with humans. App. Anim. Behav. Sci. 50, 71-82.

Imfeld-Mueller, S., Van Wezemael, L., Stauffacher, M., Gygax, L., Hillmann, E., 2011. Do pigs distinguish between situations of different emotional valences during anticipation? App. Anim. Behav. Sci. 131, 86-93.

Jago, J.G., Krohn, C.C., Matthews, L.R., 1999. The influence of feeding and handling on the development of the human-animal interactions in young cattle. App. Anim. Behav. Sci. 62, 137-151.

Jones, B.R., Waddington, D., 1992. Modification of fear in domestic chicks, Gallus gallus domesticus, via regular handling and early environmental enrichment. Animal Behaviour 43, 1021-1033.

Kanitz, E., Hameister, T., Tuchscherer, M., Tuchscherer, A., Puppe, B., 2014 in press. Social support attenuates the adverse consequences of social deprivation stress in domestic piglets. Hormones and Behavior.

Keeling, L.J., Gonyou, H.W., 2001. Social behaviour in farm animals. CAB International, Wallingford. 
Laister, S., Stockinger, B., Regner, A.-M., Zenger, K., Knierim, U., Winckler, C., 2011. Social licking in dairy cattle--Effects on heart rate in performers and receivers. App. Anim. Behav. Sci. $130,81-90$.

Marchant-Forde, R.M., Marlin, D.J., Marchant-Forde, J.N., 2004. Validation of a cardiac monitor for measuring heart rate variability in adult female pigs: accuracy, artefacts and editing. Physiology \& Behavior 80, 449-458.

Markowitz, T.M., Dally, M.R., Gursky, K., Price, E.O., 1998. Early handling increases lamb affinity for humans. Animal Behaviour 55, 573-587.

Martin, P., Bateson, P., 1994. Measuring behaviour: An introductory guide. Cambridge University Press, Cambridge (GB).

Mattiello, S., Battini, M., Andreoli, E., Minero, M., Barbieri, S., Canali, E., 2010. Avoidance distance test in goats: A comparison with its application in cows. Small Ruminant Research $91,215-218$.

Merlot, E., Mounier, A.M., Prunier, A., 2011. Endocrine response of gilts to various common stressors: A comparison of indicators and methods of analysis. Physiology \& Behavior 102, 259-265.

Merlot, E., Vincent, A., Thomas, F., Meunier-Salaün, M.-C., Damon, M., Robert, F., Dourmad, J.-Y., Lebret, B., Prunier, A., 2012. Health and immune traits of Basque and Large White pigs housed in a conventional or enriched environment. Animal 6, 1290-1299.

Mohr, E., Langbein, J., Nurnberg, G., 2002. Heart rate variability. A noninvasive approach to measure stress in calves and cows. Physiology \& Behavior 75, 251-259.

Nagasawa, M., Kikusui, T., Onaka, T., Ohta, M., 2009. Dog's gaze at its owner increases owner's urinary oxytocin during social interaction. Hormones and Behavior 55, 434-441. Paterson, A.M., Pearce, G.P., 1992. Growth, Response to Humans and Corticosteroids in Male Pigs Housed Individually and Subjected to Pleasant, Unpleasant Or Minimal Handling During Rearing. App. Anim. Behav. Sci. 34, 315-328.

Porges, S.W., 1995. Cardiac vagal tone: A physiological index of stress. Neuroscience \& Biobehavioral Reviews 19, 225-233. 

early life reduces avoidance distance and slaughter stress in beef cattle. App. Anim. Behav.

612

613

614

615

616

617

618

619

620

621

622

623

624

625

626

627

628

629

630

631

632

633

634

635

636

637

Sci.

Reefmann, N., Kaszas, F.B., Wechsler, B., Gygax, L., 2009a. Ear and tail postures as indicators of emotional valence in sheep. App. Anim. Behav. Sci. 118, 199-207.

Reefmann, N., Wechsler, B., Gygax, L., 2009b. Behavioural and physiological assessment of positive and negative emotion in sheep. Animal Behaviour 78, 651-659.

Sankey, C., Richard-Yris, M.A., Leroy, H., Henry, S., Hausberger, M., 2010. Positive interactions leat to lasting positive memories in horses, Equus caballus Animal Behaviour 79 869-875.

Schmied, C., Waiblinger, S., Scharl, T., Leisch, F., Boivin, X., 2008. Stroking of different body regions by a human: Effects on behaviour and heart rate of dairy cows. App. Anim. Behav. Sci. 109, 25-38.

Schön, P.C., Puppe, B., Manteuffel, G., 2004. Automated recording of stress vocalisations as a tool to document impaired welfare in pigs. Animal Welfare 13, 105-110.

Tallet, C., Brillouet, A., Paulmier, V., Meunier-Salaun, M., Prunier, A., 2011a. Consequences of rearing entire males on the human-animal relationship in a conventional and an enriched environment. Journees de la Recherche Porcine en France 43, 155-159.

Tallet, C., Linhart, P., Policht, R., Hammerschmidt, K., Simecek, P., Kratinova, P., Spinka, M., 2013. Encoding of situations in the vocal repertoire of piglets (Sus scrofa): a comparison of discrete and graded classifications. Plos One 8, e71841.

Tallet, C., Megnin, C., Fureix, C., Seneque, E., Meunier-Salaun, M.C., Val-Laillet, D., Morisset, S., Hausberger, M., 2011b. Development of a method to measure body posture of pigs to evaluate their welfare. Journees de la Recherche Porcine en France 43, 185-186. Tallet, C., Veissier, I., Boivin, X., 2005. Human contact and feeding as rewards for the lamb's affinity to their stockperson. App. Anim. Behav. Sci. 94, 59-73.

Tallet, C., Veissier, I., Boivin, X., 2006. Does the use of a device to measure heart rate affect the behavioural responses of lambs to humans? App. Anim. Behav. Sci. 99, 106-117. 
638 Tallet, C., Veissier, I., Boivin, X., 2009. How does the method used to feed lambs modulate 639 their affinity to their human caregiver? App. Anim. Behav. Sci. 119, 56-65.

640 Talling, J.C., Waran, N.K., Wathes, C.M., Lines, J.A., 1996. Behavioural and physiological 641 responses of pigs to sound. App. Anim. Behav. Sci. 48, 187-201.

642 Tanida, H., Miura, A., Tanaka, T., Yoshimoto, T., 1994. The Role of Handling in

643 Communication Between Humans and Weanling Pigs. App. Anim. Behav. Sci. 40, 219-228.

644 Terlouw, E.M.C., Porcher, J., 2005. Repeated Handling of Pigs During Rearing. I. Refusal of 645 Contact by the Handler and Reactivity to Familiar and Unfamiliar Humans. Journal of Animal 646 Science 83, 1653-1663.

647 Torrey, S., Widowski, T.M., 2006. Is belly nosing redirected suckling behaviour? Applied 648 Animal Behaviour Science 101, 288-304.

649 Turner, S.P., Farnworth, M.J., White, I.M.S., Brotherstone, S., Mendl, M., Knap, P., Penny, 650 P., Lawrence, A.B., 2006. The accumulation of skin lesions and their use as a predictor of 651 individual aggressiveness in pigs. App. Anim. Behav. Sci. 96 245-259.

652 Val-Laillet, D., Guesdon, V., von Keyserlingk, M.A.G., de Passille, A.M., Rushen, J., 2009. 653 Allogrooming in cattle: Relationships between social preferences, feeding displacements and 654 social dominance. Applied Animal Behaviour Science 116, 141-149.

655 von Borell, E., Langbein, J., Despres, G., Hansen, S., Leterrier, C., Marchant-Forde, J., 656 Marchant-Forde, R., Minero, M., Mohr, E., Prunier, A., Valance, D., Veissier, I., 2007. Heart 657 rate variability as a measure of autonomic regulation of cardiac activity for assessing stress 658 and welfare in farm animals -- A review: Stress and Welfare in Farm Animals. Physiology \& 659 Behavior 92, 293-316.

660 Ruis, M.A.W., te Brake, J.H.A., Engel, B., Buist, W.G., Blokhuis, H.J., Koolhaas, J.M., 2001. 661 Adaptation to social isolation - Acute and long-term stress responses of growing gilts with 662 different coping characteristics. Physiology \& Behavior 73, 541-551.

663 Waiblinger, S., 2009. Human-Animal Relations. In: Jensen, P. (Ed.), The ethology of 664 domestic animals 2nd edition- an introductory text. CAB International, UK pp. 102-117. 
665 Waiblinger, S., Boivin, X., Pedersen, V., Tosi, M.-V., Janczak, A.M., Visser, E.K., Jones,

666 R.B., 2006. Assessing the human-animal relationship in farmed species: A critical review.

667 App. Anim. Behav. Sci. 101, 185-242.

668 Weary, D.M., Appleby, M.C., Fraser, D., 1999. Responses of piglets to early separation from

669 the sow. App. Anim. Behav. Sci. 63, 289-300.

670 Zonderland, J.J., van Riel, J.W., Bracke, M.B.M., Kemp, B., den Hartog, L.A., Spoolder,

671 H.A.M., 2009. Tail posture predicts tail damage among weaned piglets. App. Anim. Behav.

672 Sci. 121, 165-170.

673 
Figures captions

Figure 1. Mean ( \pm sem) time spent near the handler and looking at the handler for control $(H 0, n=16$, light grey) and handled $(H 1, n=15$, hatched) piglets during phases 1 and 3 (human presence) of Test 2.

For "near the handler", the interaction between treatment and phase is not significant $(P>$ 0.1). The effects of phase or treatment are shown by asterisks: *: $P<0.05 ;{ }^{* *}: P<0.01$.

For "looking at handler", the interaction between treatment and phase is significant $(P<$ 0.05). Comparisons between means are shown by letters a,b,c: values with different letters differ significantly $(P<0.05)$.

Figure 2. Change in median ( \pm quartiles) (a.) number of low-pitched vocalizations, (b.) time spent investigating the handler (s), and (c.) time spent without contact with the handler (s) according to the treatment (light grey: control $=\mathrm{HO}$, and black: handled $=\mathrm{H} 1$ ) and the phases of Test 3 (Hsat = handler immobile, Strok1 and $2=$ handler stroking the piglets, $\mathrm{ScratH}=$ handler scratching the head of the piglet, ScratR = handler stroking the piglet at its rear). Treatment effect by phase: $\mathrm{t}: 0.05<P<0.1 ; * *$ : $P<0.01 ; * *$ : $P<0.001$.

Phase effect within a treatment: values with different letters differ significantly $(P<0.05)$; a,b,c (black) correspond to $\mathrm{H} 1$ treatment, and d,e,f (grey) to HO treatment.

Figure 3. Change in mean ( \pm sem) heart rate (a.) and RMSSD (b.) according to the treatment (light grey: control $=\mathrm{HO}$, and black: handled $=\mathrm{H} 1$ ) and the phases of Test 3 (Alone= piglet alone, Hsat $=$ handler immobile, Strok1 and $2=$ handler stroking the piglets, ScratH $=$ handler scratching the head of the piglet, ScratR = handler stroking the piglet at its rear).

Treatment effect by phase: $* *: P<0.01$.

Phase effect: values with different letters differ significantly $(P<0.05)$.

$A, B$ correspond to phase effect for both treatments, a,b,c (black) correspond to $\mathrm{H} 1$ treatment, and d,e,f (grey) to HO treatment. 
702 Figure 4. Mean ( \pm sem) salivary cortisol concentration $(\mathrm{ng} / \mathrm{ml})$ of control piglets $(\mathrm{H} 0)$ and 703 handled piglets (H1) after a period of $15 \mathrm{~min}$ of isolation or $15 \mathrm{~min}$ of human contact (Test 4).

704

705

706

707

708 


\begin{tabular}{|c|c|c|c|c|c|c|}
\hline $\begin{array}{l}\text { Day of the } \\
\text { experiment }\end{array}$ & $\begin{array}{c}\text { Pigs' } \\
\text { age in } \\
\text { days ( }( \pm \\
\text { 2) }\end{array}$ & Test & Period & Event / observation & Place & Observation \\
\hline 0 & 28 & & Morning & Weaning & & \\
\hline $1-25$ & $29-53$ & & Morning + afternoon & Sessions of human contact & Home pen & - \\
\hline 25 & 53 & & Afternoon & Reaction to human presence & Home pen & Behaviour \\
\hline $26-27$ & $54-55$ & 1 & Morning & $\begin{array}{l}\text { Reaction to human presence and } \\
\text { departure }\end{array}$ & Arena test & Behaviour \\
\hline 32 & 60 & 2 & Morning + afternoon & Two sessions of human contact & Home pen & - \\
\hline \multirow[t]{2}{*}{$33-35$} & $61-63$ & 3 & Morning & Reaction to human contact & Test pen & $\begin{array}{c}\text { Behaviour and cardiac } \\
\text { activity }\end{array}$ \\
\hline & & & Afternoon & One session of treatment & Home pen & - \\
\hline $40-43$ & $68-71$ & 4 & Afternoon & $\begin{array}{l}\text { Reaction to isolation and human } \\
\text { presence }\end{array}$ & Test pen & $\begin{array}{c}\text { Behaviour and salivary } \\
\text { cortisol }\end{array}$ \\
\hline
\end{tabular}


Table 2. Behavioural observations during the different tests of the experiment

behaviour

description

used in tests

Interactions with the handler

Look at the handler

Head directed to the handler

1,2

Investigation of the handler

Head of the piglet in contact with the

$1,2,3,4$

handler (touching or sniffing)

Body contact

Animal standing and in contact (any part

$1,3,4$ of the body except the head) with the handler

Body contact lying

Animal lying down or sitting (any part of

3,4 the body except the head) in contact

with the handler

Climb

The piglet climbs on the handler, with at least its front legs on the thighs of the

$1,2,3,4$

Vocalisations

High-pitched vocalizations

Screams, squeals and grunt-squeals

2,3

Low-pitched vocalizations

grunts

2, 3

\section{Locomotion}

Number of zones crossed Total number of zone crossed during the

test. The animal was considered to enter

a zone when its two front legs were in the zone.

\section{Other behaviours}

Bucket contact

In contact with the bucket on which the handler is seated

No contact

No contact with the handler

1,3

Avoidance

The piglet moves away from the handler, or turns its head opposite to the handler

Escape

$$
\text { Attempt to escape from the pen, by }
$$
jumping against the walls 
Table 3. Evolution of the mediane (IQ) heart rate (beat per minute) of the piglets according to the behaviour of the handler during the different phases of Test 3 (Hsat = handler immobile, Strok1 and $2=$ handler stroking the piglets, ScratH = handler scratching the head of the piglet, ScratR $=$ handler stroking the piglet at its rear).

\section{H0 treatment $\quad \mathrm{H} 1$ treatment}

\begin{tabular}{ccccccccc} 
phase of test & variation & $\boldsymbol{N}$ & $\boldsymbol{Z}$ & $\boldsymbol{P}$ & variation & $\boldsymbol{N}$ & $\boldsymbol{z}$ & $\boldsymbol{P}$ \\
\hline between Alone and Hsat & $26(46)$ & 10 & $\mathbf{2 . 0 9}$ & $\mathbf{0 . 0 4}$ & $15(25)$ & 8 & $\mathbf{2 . 1 0}$ & $\mathbf{0 . 0 4}$ \\
\hline between Hsat and Strok1 & $-5(10)$ & 10 & 1.48 & 0.14 & $-5(15)$ & 8 & 1.40 & 0.16 \\
\hline between Strok1 and ScratH & $-1(8)$ & 10 & 0.56 & 0.58 & $0(14)$ & 7 & 0.85 & 0.40 \\
\hline between ScratH and Strok2 & $-4(4)$ & 10 & 1.78 & 0.07 & $\mathbf{- 5 ( 5 )}$ & 9 & $\mathbf{2 . 1 9}$ & $\mathbf{0 . 0 3}$ \\
\hline between Strok2 and ScratR & $-2(3)$ & 11 & 0.98 & 0.33 & $\mathbf{- 5 ( 4 )}$ & 10 & $\mathbf{2 . 2 9}$ & $\mathbf{0 . 0 2}$ \\
\hline
\end{tabular}




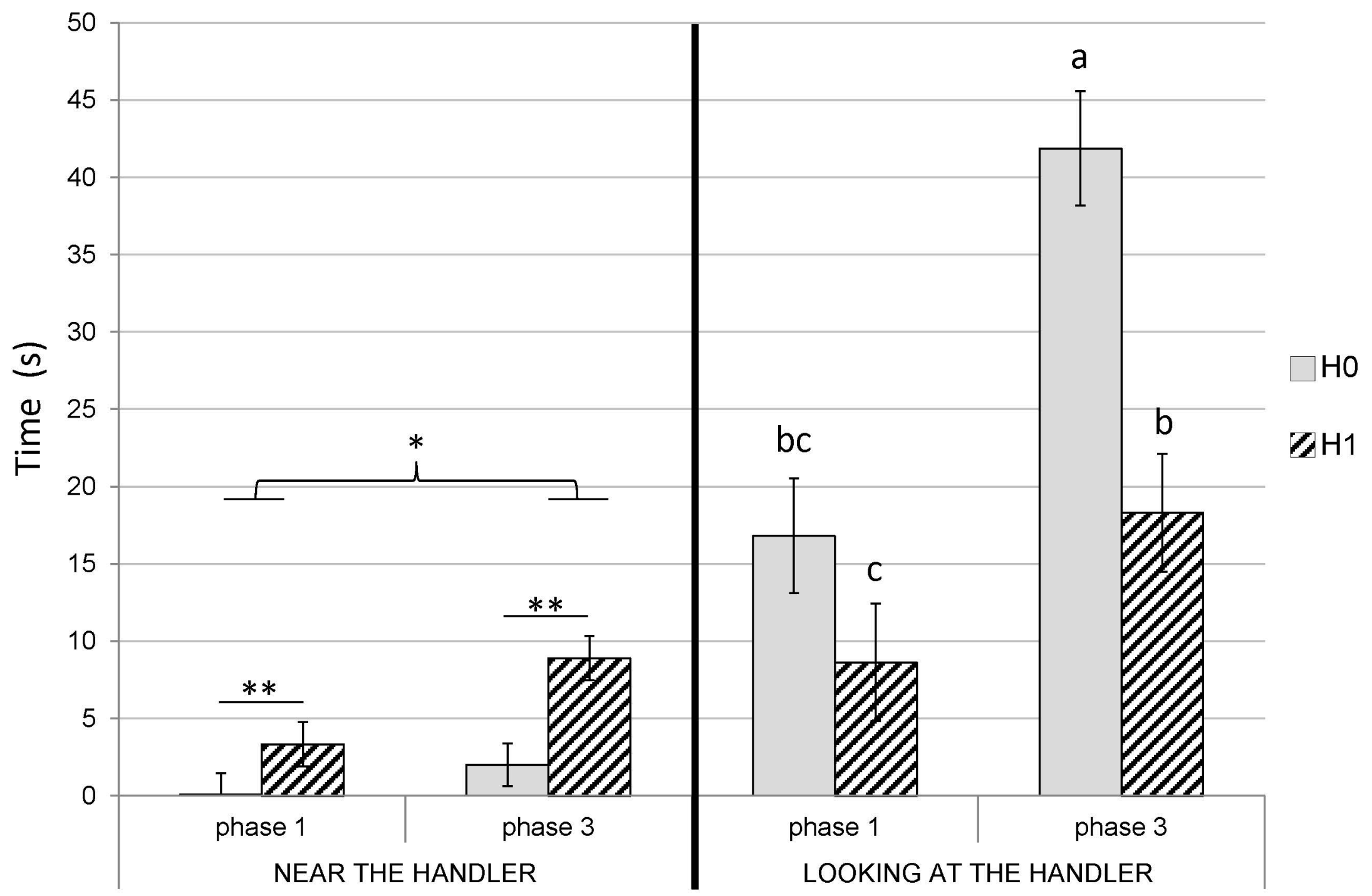




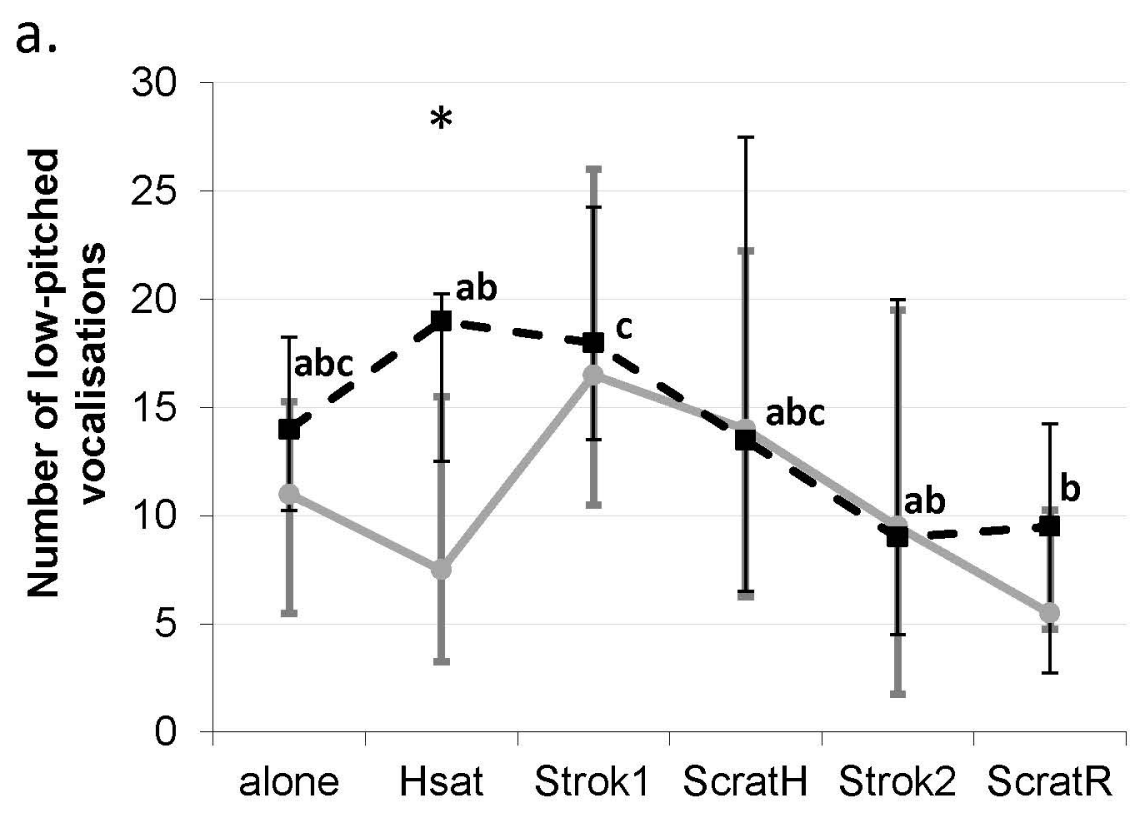

b.

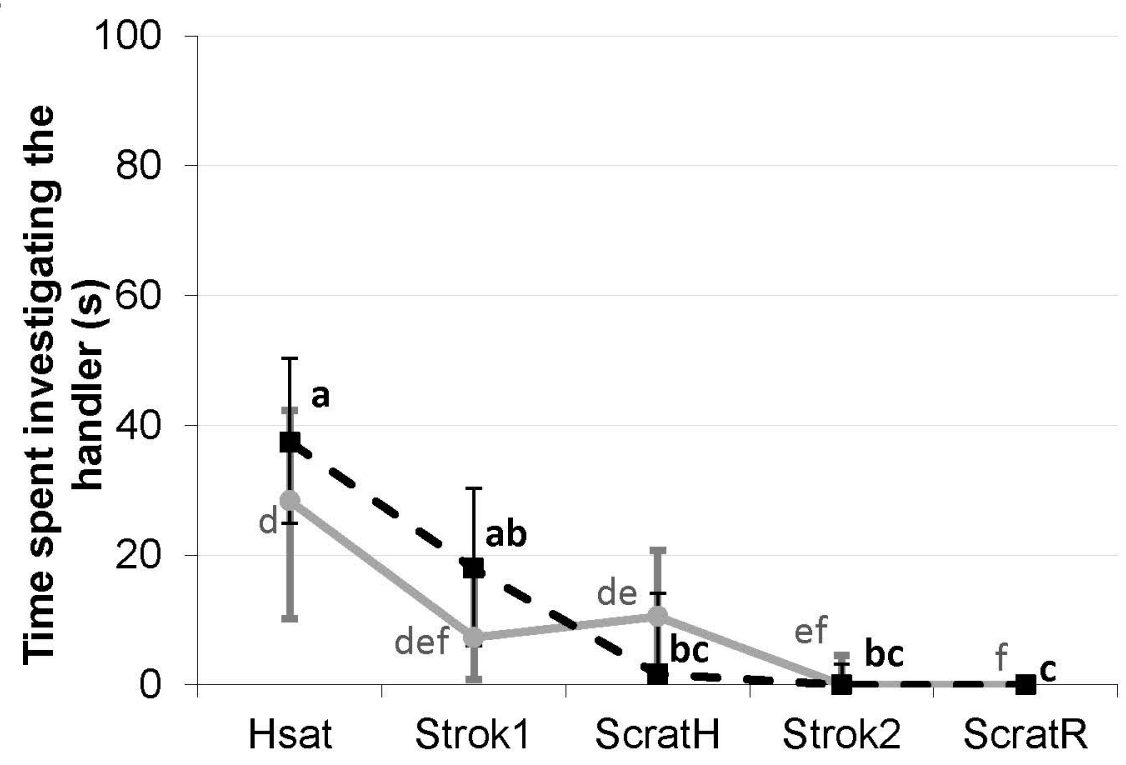

c.

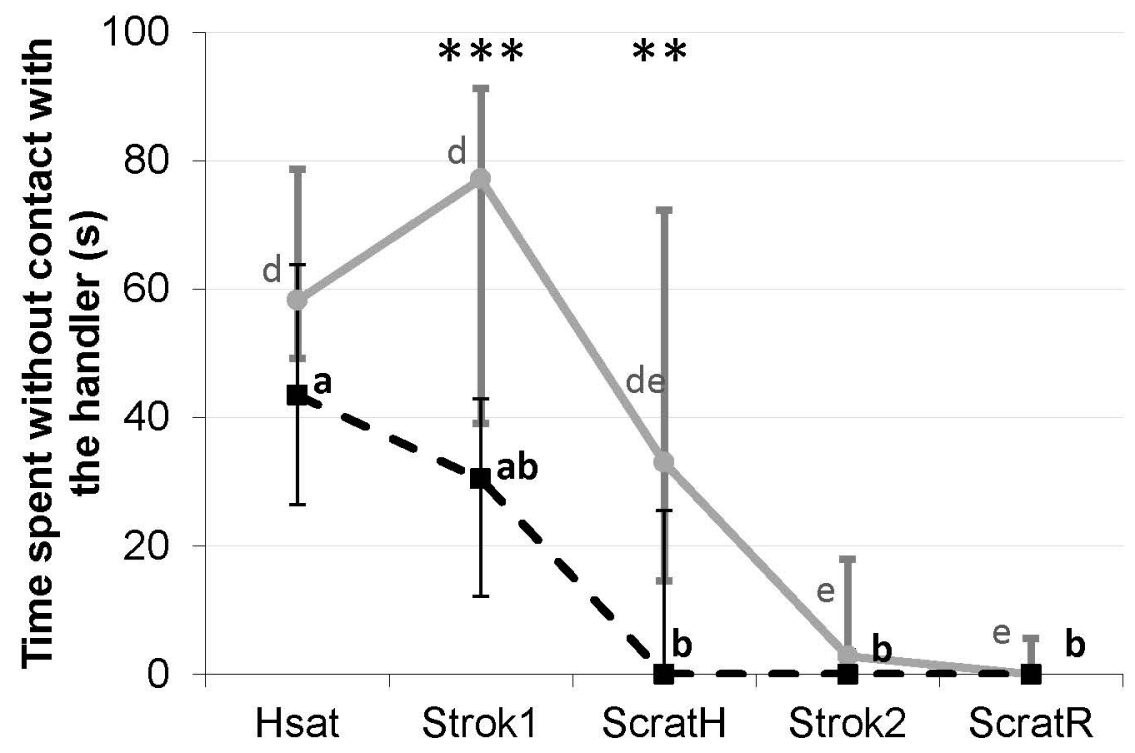


a.

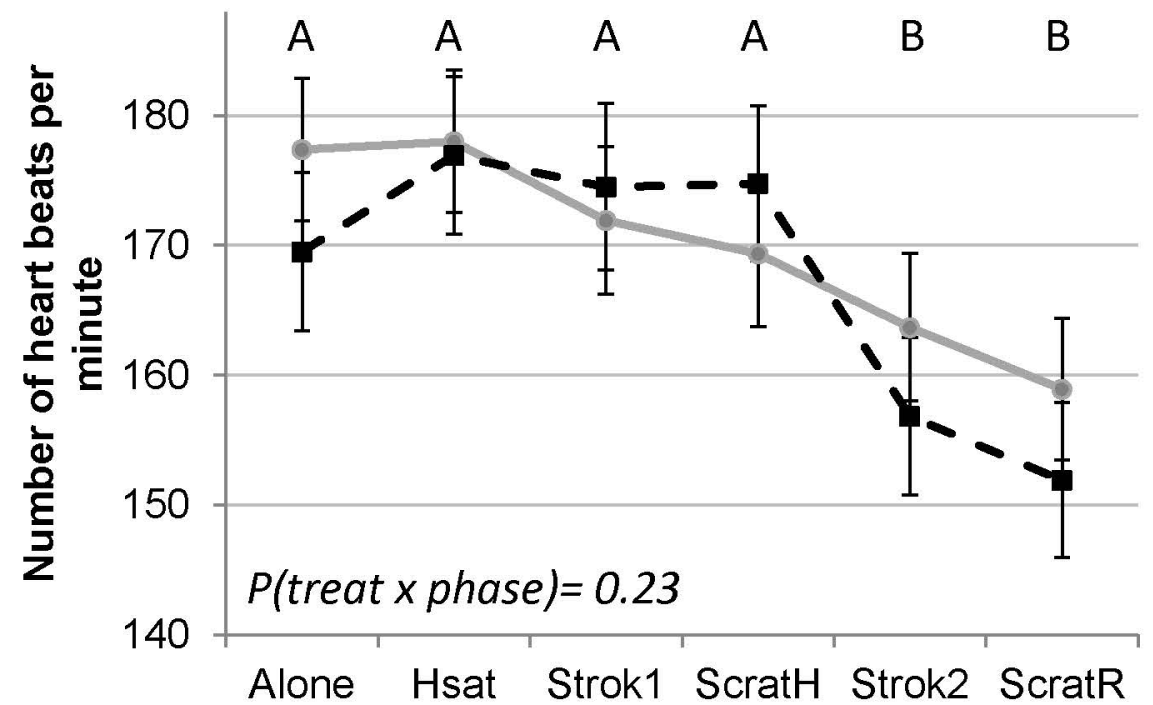

b.

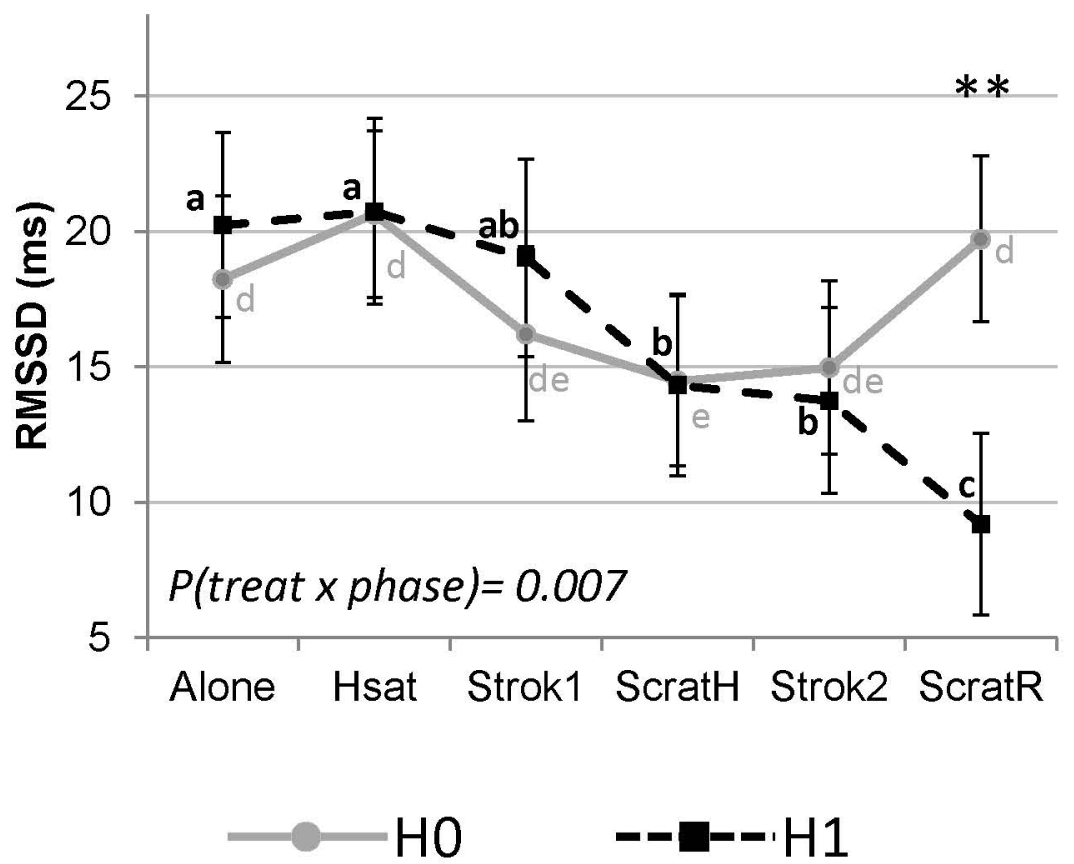


Cortisol concentration ( $\mathrm{ng} / \mathrm{ml}$ )

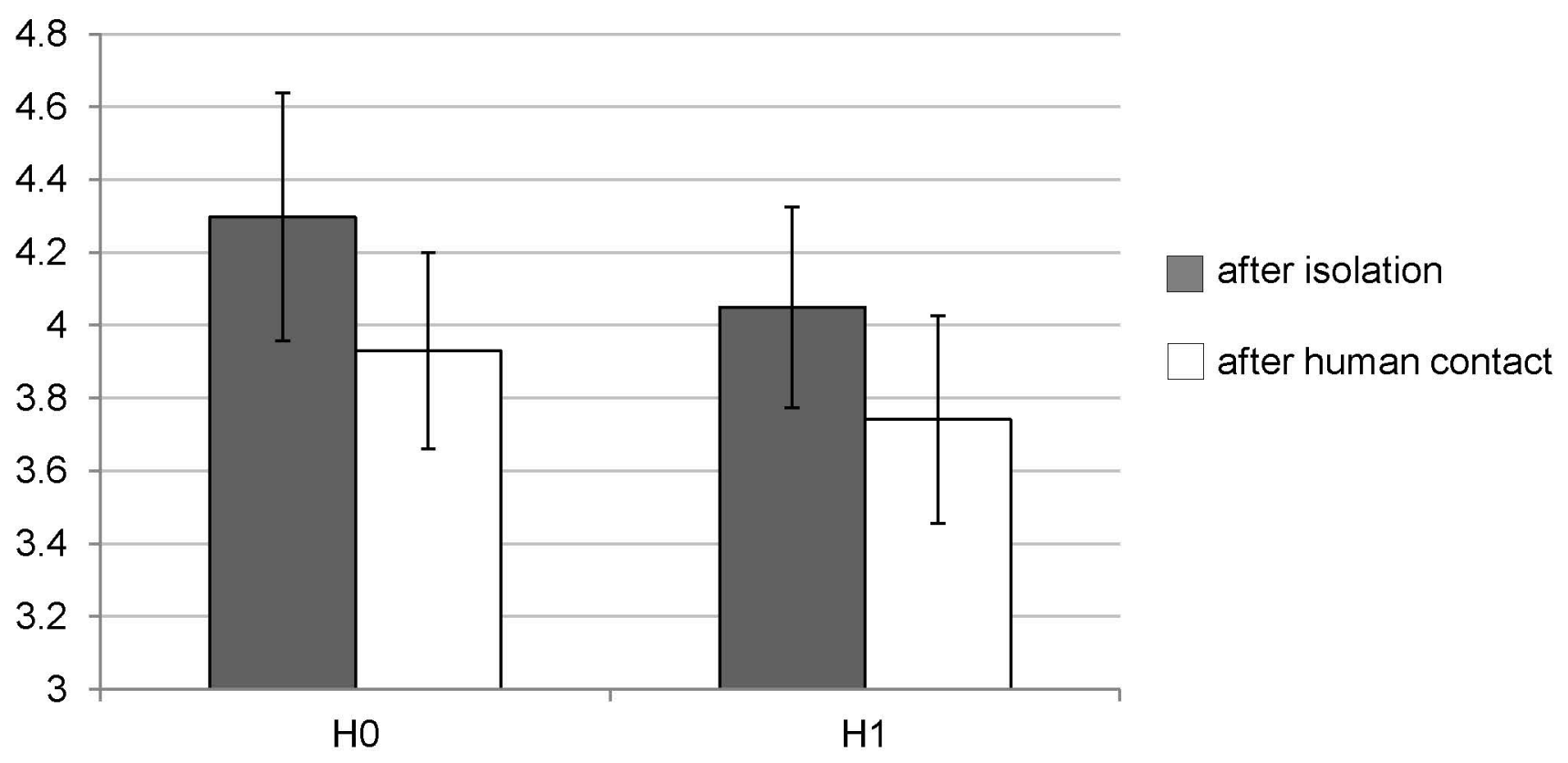

